\title{
Dengue hemorrágico y eclampsia Reporte de un caso
}

\author{
Rodrigo Cifuentes B. MD.*; Orlando Abonía MD**; Fernando Rosso MD***
}

\section{RESUMEN}

La incidencia de dengue ha aumentado dramáticamente en Cali en los últimos años, con epidemias durante 1992 y 1995. Durante 1997 se registró mas de 930 casos sospechosos y 433 serológicamente confirmados de su forma grave: el dengue hemorrágico (DH), cobró la vida de 6 personas. El brote epidémico aunado a la alta tasa de natalidad y prevalencia de preeclampsia (13.5\%) en la ciudad, favorece la asociación de estas entidades en la temporada.

Se presenta el caso de una primigestante de 20 años, embarazo de 36,5 semanas; con 5 días de fiebre alta, cefalea intensa, osteomialgias, gingivorragias, epistaxis, hematemesis, melenas, edemas, trombocitopenia progresiva hasta $10.000 \mathrm{plaq} / \mathrm{mm}^{3}$ y títulos IgM ELISA (+) para dengue, quien desarrolla preeclampsia de rápida evolución a eclampsia.

Se induce parto vaginal obteniendo neonato sano de $3.200 \mathrm{grs}$., con choque materno durante el alumbramiento "desproporcionado" al volumen clínico de sangrado.

Se propone aumentar el reporte de casos que sumen evidencias para dilucidar la hipótesis, que el DH empeora el curso de la preeclampsia; como se sospecha por los casos manejados en el Hospital Universitario del Valle (HUV) y otros reportados en la literatura.

PALABRAS CLA VES: Dengue hemorrágico, preclampsia, eclampsia.

\section{SUMMARY}

The dengue of incidence has increased dramatically in Cali in the last years, with epidemic outbreaks during 1992 and 1995 . In 1999 more than 930 suspicious cases were registred and $\mathbf{4 3 3}$ serology for confirmed in their serious form: The hemorrhagic dengue (HD), they charged the life of 6 persons. The epidemic bud joined to the highs rates of natality and preeclamspia prevalency $(13.5 \%)$ in the city, they favor the association of these entitles in the season.

The case of a 20 year-old woman with pregnancy of 36,5 weeks is presented; to entrance with 5 days of high fever, intense headache, pain osteomuscular, gingivorrhagy, epistaxis, hematemesis manes, edemas, progressive throbocytopenia up to $10.000 \mathrm{plaq} . / \mathrm{mm}$ and title IgmELISA for dengue positive, who develops preeclampsia of quick evolution to eclampsia. Vaginal childbirth "unconventional" to the clinical volumen of having bled.

We intends to increase the report of cases that they add evidences to elucidate the hypothesis: That the DH worsens the course of the preeclampsia, as it is suspected by the cases managed in the University Hospital of the Valley (HUV) and others reportes in the literature.

KEY WORDS: hemorrhagic dengue, preclampsia, eclampsia.

\section{Introducción}

El dengue, es una enfermedad viral cosmopolita en los países tropicales desde hace mas de 200 años, inicialmente considerada como enfermedad febril benigna hasta la aparición de los primeros casos hemorrágicos fatales.

\footnotetext{
* Ph. D. Profesor Titular Emérito, Departamento de Ginecología y Obstetricia Universidad del Valle, Cali, Colombia. E-mail: rocifuen@ col2.telecom.com.co

Jefe de Residentes, Departamento de Ginecología y Obstetricia, Universidad del Valle.E-mail: Orlandoabonía@hotmail.com Internista y Epidemiólogo. Profesor Adjunto, Dpto. Medicina Interna - Universidad del Valle, Sría. Salud Pública Municipal de Cali.
}

La fiebre por dengue hemorrágico (FDH) hizo debut en el sureste Asiático en 1779 (11); causando desde entonces brotes epidémicos en los tres continentes sin comprensión clara del cambio de virulencia del agente. La infortunada epidemia mayor en América (Cuba 1981) con 350.000 casos y 158 muertes, dejó invaluables conocimientos en el comportamiento clínico y epidemiológico de la entidad (12).

Aparece en Colombia en diciembre de 1989 con 34 casos y una defunción, desde entonces ha presentado brotes intercurrentes en 1992 y 1995, distribuidos en varias regiones del país, especialmente en Santander y Valle del Cauca (5). 
En la ciudad de Cali (Capital del último departamento) donde el dengue es endémico, su variedad hemorrágica (DH) usualmente era inferior al 5\% (1). Durante el brote epidémico de 1997 su tasa de presentación se incrementa de 4.8 a $9.2 \times 100.000 / \mathrm{Hab}$, registrándose mas de 930 casos sospechosos y 433 confirmados serológicamente, que cobraron la vida de 6 personas (2); este dramático ha aumentado en los últimos años y se ha atribuido a la alta circulación del virus e infestación de su vector como consecuencia de nuevos fenómenos climáticos.

\section{Caso}

Se presenta el caso de una mujer indígena de 20 años, primigestante con embarazo de 36.5 semanas quien es remitida por cuadro de cinco días de fiebre, cefalea intensa, osteomialgias, dolor retro-ocular, oliguria; y dos días de epistaxis, hematemesis, melenas, descenso de su recuento plaquetario desde 100 a 10.000 plaq. $/ \mathrm{mm}^{3}$ y sospecha de trastorno hipertensivo. Ingresa en I-18-98 afebril, con TA: $140 / 90$, proteinuria cualitativa $(-)$, equímosis, petequias, prueba del torniquete (+) altura uterina: $30 \mathrm{~cm}$, FCF: 140x", cérvix sin cambios, y edema $\mathrm{G}^{0} \mathrm{II}$ de miembros inferiores. Se inicia manejo agresivo con cristaloides y se documenta una preeclampsia por cifras diastólicas > $90 \mathrm{mmHg}$ y proteinuria de $24 \mathrm{Hrs}$ (Ver tabla 1).

En junta perinatológica multidisciplinaria se decide manejo expectante hasta recuperación hematológica; con plaquetas de 44.000 plaq $/ \mathrm{mm}^{3}$, epistaxis y TAD: 95$100 \mathrm{mmHg}$ presenta episodio tonico-clónico generalizado. Previa estabilización materno-fetal, goteo de sulfato de $\mathrm{Mg}$ y Bishop de 6, se induce el parto. A las 10h. se obtiene RN de 3250g., APGAR de 8/10, sin diátesis hemorrágica.

Durante el alumbramiento con sangrado aparentemente usual, presenta choque hipovolémico que responde a cristaloides, coloides, oxitócicos y masaje uterino.

Al tercer día puerperal se da de alta sin secuelas y en buenas condiciones generales, con 123.000 plaq. $/ \mathrm{mm}^{3}$, previa transfusión de una unidad de glóbulos rojos, tratamiento con albendazol para strongyloidiasis y títulos Elisa IgM (+) para dengue e IHA.

\section{Discusión}

Toda vez que la infección por virus-dengue no hace distingo de raza, edad, ni sexo, la confluencia tripartita en la ciudad de alta tasa de natalidad, incidencia de preeclampsia doble que la población general $(13 \%)(2,5)$ y un vector eficiente; hacen tan probable esta asociación, que resulta interesante analizar el comportamiento clínico en un embarazo complicado simultáneamente con preeclampsia/eclampsia y dengue hemorrágico.

Justo en días previos a la publicación de este caso se confirmaron en nuestro Servicio de Obstetricia del HUV otros tres casos adicionales de DH: uno en otra primigestante también con aparición y deterioro intrahospitalario de preeclampsia; una multípara con sufrimiento fetal agudo quien debió ser operada de urgencia con 14.000 plaquetas, y otra mujer a quien le practican cesárea electiva por distocia pélvica, ingresa remitida 12 horas después en choque y coagulopatía franca; manejada en UCI durante dos meses, con sangrado incoercible durante una semana que ameritó transfusión de 65 unidades de diferentes preparados hemáticos y finalmente sale viva sin secuelas neurológicas.

No obstante la creciente incidencia de $\mathrm{DH}$, pensamos que sería el segundo reporte de esta asociación en la literatura revisada (10).

Es muy llamativo en este caso la evolución rápida y abrupta a eclampsia mientras se discutían otros diagnósticos diferenciales. Si bien unos pocos casos no dan elementos de juicio suficientes, ni la mejor evidencia que permita sacar conclusiones definitivas; su análisis epidemiológico deja importantes interrogantes e inferencias por resolver.

Se alerta si estos y otros casos reportados (10), pueden considerarse indicios sugestivos de mal curso

Tabla 1

EVOLUCION DIARIA DE LABORATORIO

\begin{tabular}{|l|c|c|c|c|c|c|}
\hline Laboratorio/día & $\mathbf{1}$ & $\mathbf{2}$ & $\mathbf{3}$ & $\mathbf{4}$ & $\mathbf{5}$ & $\mathbf{6}$ \\
\hline Hb / Hcto. & $11 / 34$ & - & $10 / 33$ & $10.5 / 32$ & $5 / 16$ & $6.7 / 22$ \\
Plaquetas & 28.000 & 44.000 & 82.000 & 98.000 & 108.000 & 23.000 \\
Coombs & $(-)$ & - & - & - & - & - \\
BT / ALS / ALT & $2.8 / 68 / 27$ & - & $1.5 / 61 / 30$ & $1.3 / 64 / 32$ & - & - \\
Creatinina & 0.7 & - & 0.7 & 0.8 & 0.8 & \\
Proteinuria & & $330 \mathrm{mg} / 24 \mathrm{~h}$. & & & & \\
PT - PTT & 347 & $10.2 / 25$ & & & & \\
LDH & 857 & & & & & \\
Otros & & $80-90 / 110$ & $90-95$ & & & \\
TAD (mmHg.) & Reactiva & Reactiva & Reactiva & & & \\
PNE & & & & & \\
\hline
\end{tabular}


de los trastornos hipertensivos del embarazo cuando se asocia a DH, probablemente explicado por un efecto sumatorio del daño endotelial y aumento de la permeabilidad capilar en las dos entidades, que resultan en hemoconcentración, hipovolemia, CID, "choque séptico" por virus y alteraciones de otros órganos de la economía comparable a falla orgánica múltiple. No obstante estos cambios, y la conocida respuesta inmunológica con liberación de citoquinas, mediadores químicos de células $\mathrm{T}$, monocitos infectados y linfocitos T citotóxicos activados; "In vitro" la infección directa del virus dengue solo produce edema de las células endoteliales sin daño de la membrana basal y no se ha podido demostrar reacción inflamatoria ni se ha aislado el virus del endotelio vascular (5).

En los casos nuestros y la literatura, no se encontró datos sobre mal resultado perinatal y aunque hacen falta mas estudios, a la fecha no se acepta con claridad la transmisión vertical del virus. La trombocitopenia per se tampoco parece afectarlo.

El DH es una entidad de presentación clínica polimorfa, con complicaciones mortales, entraña difícil diagnóstico diferencial con otras patologías propias del embarazo como: hígado graso, Síndrome Hellp, preeclampsia severa, y aún el mismo dengue clásico con manifestaciones hemorrágicas menores, lo que podría resultar en intervenciones tardías en pacientes con cuadros bizarros. Ayuda la historia clínica precisa, evolución de la paciente, evaluación del bienestar fetal y algunas particularidades de los exámenes de laboratorio. Es prudente interconsultar a otras especialidades para esclarecer el diagnóstico diferencial.

En nuestro caso, la paciente reunió todos los criterios diagnósticos de la OMS y cabría preguntar si su hemoglobina inicial era real o padecía una anemia enmascarada por hemoconcentración, que explique el severo compromiso hemodinámico en el alumbramiento con un volumen de sangrado intraparto aparentemente usual en una paciente malnutrida, sin control prenatal adecuado y parasitismo hematófago importante.

En cuanto al episodio convulsivo, si se acepta que el $31 \%$ de los casos de eclampsia son imprevisibles (4) y el $10 \%$ aparecen sin signos y síntomas de preeclampsia previos (3), la clínica en este caso es muy sugestiva de eclampsia aunque podría considerarse la posibilidad de compromiso neurológico viral, puesto que en la epidemia cubana se observó edema cerebral, hemorragias subaracnoideas focales y encefalitis esporádica causante de convulsiones como se reportó recientemente (6-8).

\section{Conclusión}

Conscientes de la dificultad que revisten los estudios clínicos controlados en esta entidad y sin la mejor evidencia, pensamos hay indicios que sugieren que la presencia de DH durante el embarazo podría favorecer la aparición y evolución agresiva de preeclampsia. Faltan reportes y estudios que diluciden esta hipótesis, por lo que exhortamos a las comunidades científicas mundiales y en especial de países tropicales a elaborar publicaciones sobre su experiencia en el tema.

El riesgo latente de sangrado incoercible en estas pacientes, invita a diferir en lo posible cualquier procedimiento quirúrgico.

Dado que no se dispone de vacuna ni cura para ninguna de las dos entidades, solo la prevención y un manejo agresivo reducirían su morbi-mortalidad.

\section{Agradecimientos}

Al Servicio de Estadística del Hospital Universitario del Valle, al Centro informático CEMIYA, al Departamento de Virología de la Universidad del Valle y al grupo de epidemiología de la Secretaría de Salud Municipal de Santiago de Cali; por su invaluable colaboración.

\section{BIBLIOGRAFIA}

1. Rosso F. Dengue Hemorrágico: Diagnóstico y Tratamiento - Monografía No. 1, Secretaría de Salud Pública Municipal, Santiago de Cali, 1997.

2. Muñoz J. Boletín Informativo: Enfermedades Transmitidas por vectores, Secretaría de Salud Pública Municipal Santiago de Cali, 1997.

3. Cifuentes R. Hipertensión Arterial y Embarazo. Obstetricia de Alto Riesgo, 4a. Ed, Editorial Aspromédica, Cali, Col., 1994; 548.

4. Sibai BM., Anderson GD et al. Eclampsia: IV, The incidence of nonpreventable eclampsia. Am. J Obstet Gynecol. 1986; 154: 581586.

5. Moreno $\mathrm{CH}$. \& Rosso F. Deñgue hemorrágico en emergencias en Medicina Interna, 2a. Ed., Aspromédica, Cali, Colombia, 1997; 386402 .

6. Ortiz I. Patologías Maternas, Sistema Informático Perinatal CLAPOPS/OMS (CEMIYA), HUV, Cali, Col., Feb. 1998.
7. OMS. Dengue hemorrágico: Diagnóstico, tratamiento y lucha. Ginebra. OMS 1987.

8. OPS. Dengue y dengue hemorrágico en las Américas: Guías para la prevención y control. Publicación científica de la OPS № 548, 1995.

9. Ramirez-Ronda \& García CD. Dengue in the western hemisphere. Infec Dis Clin North America, 1994; 8: 107-128.

10. Bunyavejchevin S., Tanwattanacharoen S., Taecchakraichana and Col. Dengue hemorrhagic fever during pregnancy: antepartum, intrapartum and postpartum management, J Obstet Gynaecol Res 1997; 23(5): 445-448.

11. Bull-Soc-Pathol-Exot. 1996; 89(2): 91-3; discussion 93-4. Cochrane 1997.

12. Braunwald E. and Othrers Harriso's. Principels of Internal Medicine, Ed. 14a., Ed. McGraw Hill, 1997. 